\section{SLE news.}

\section{OP0246 ATTAINMENT OF THE LUPUS LOW DISEASE ACTIVITY STATE IS ASSOCIATED WITH PROTECTION FROM DAMAGE ACCRUAL IN PATIENTS WITH ACTIVE DISEASE AT BASELINE}

Vera Golder ${ }^{1,2}$, Eric F. Morand ${ }^{1,2}$, Rangi Kandane-Rathnayake ${ }^{1,2}$, Molla Huq $^{3}$, Hieu $\mathrm{Nim}^{1}$, Worawit Louthrenoo ${ }^{4}$, Shue Fen Luo ${ }^{5}$, Yeong-Jian Wu ${ }^{5}$, Aisha Lateef ${ }^{6}$, Sargunan Sockalingam ${ }^{7}$, Sandra Navarra ${ }^{8}$, Leonid Zamora ${ }^{8}$, Laniyati Hamijoyo ${ }^{9}$, Yasuhiro Katsumata ${ }^{10}$, Masayoshi Harigai ${ }^{10}$, Madelynn Chan ${ }^{11}$, Sean O'neill ${ }^{12}$, Fiona Goldblatt ${ }^{13}$, Chak Sing Lau ${ }^{14}$, LI Zhanguo ${ }^{15}$, Alberta Hoi ${ }^{1,2}$, Mandana Nikpour ${ }^{3}$, Asia Pacific Lupus Collaboration. ${ }^{1}$ Monash University, Clayton Campus, Clayton, Australia; ${ }^{2}$ Monash Medical Centre, Clayton, Australia; ${ }^{3}$ University of Melbourne, Parkville, Australia; ${ }^{4}$ Chiang Mai University, Chiang Mai, Thailand; ${ }^{5}$ Chang Gung Memorial Hospital, Guishan, Taiwan, Republic of China; ${ }^{6}$ National University Hospital, Singapore, Singapore; ${ }^{7}$ University of Malaya, Kuala Lumpur, Malaysia; ${ }^{8}$ University of Santo Tomas Hospital, Manila, Philippines; ${ }^{9}$ Padjadjaran University, Bandung, Indonesia; ${ }^{10}$ Tokyo Women's Medical University, Shinjuku, Japan; ${ }^{11}$ Tan Tock Seng Hospital, Singapore, Singapore; ${ }^{12}$ Liverpool Hospital School, Liverpool, Australia; ${ }^{13}$ West Terrace, Adelaide, Australia; ${ }^{14}$ University of Hong Kong, Hong Kong, Hong Kong (SAR); ${ }^{15}$ Peking University, Beijing, China

Background: The recently validated Lupus Low Disease Activity State (LLDAS) definition has been shown to have utility as a treat to target endpoint in SLE, whereby LLDAS attainment is associated with reduction in permanent damage accrual. Robust evaluation is required to ensure this protective association is not simply reflective of milder disease phenotypes being over-represented among LLDAS attainers.

Objectives: To assess the effect of attainment of LLDAS on damage accrual in patients with active disease at baseline. SLEDAI-2K $\geq 6$ was chosen as this reflects clinical trial entry criteria.

Methods: A prospective multinational cohort study was undertaken in 13 centres between 2013-2017. Patients with SLE were recruited, SLEDAI-2k, SELENA flare index, PGA, and medication data collected at every visit, and damage score (SLICC-ACR damage index (SDI)) collected annually. Subgroup analyses were performed to assess the effect of LLDAS on damage accrual in patients who had active disease at baseline (SLEDAI-2K $\geq 6$ ). Time-dependent hazards regression models were used to assess the association of attainment of LLDAS at any time point, and proportion of time in LLDAS at the $50 \%$ observed time cut-off, with accrual of irreversible end-organ damage.

Results: 1,735 patients were followed for (mean \pm SD) $2.2 \pm 0.9$ years, totalling 12,717 visits. LLDAS attainment was less frequent in patients with active disease at baseline (901 of 3835 visits in LLDAS, 23.5\%), compared to patients with SLEDAI2-K<6 at baseline ( 5190 of 8845 visits in LLDAS, $58.7 \%$ ), $p<0.001$. In contrast, compared to those with baseline SLEDAI- $2 \mathrm{~K}<6$, patients with active disease at baseline demonstrated a stronger association of LLDAS attainment with reduction in risk of damage accrual, in visit by visit analysis (HR $0.49,95 \% \mathrm{Cl} 0.28-0.86, \mathrm{p}$ 0.01 vs $\mathrm{HR} 0.72,95 \% \mathrm{Cl} 0.52-0.99, \mathrm{p} 0.05$ ), and in analysis of cumulative time spent in LLDAS (HR $0.52,95 \% \mathrm{Cl} 0.33-0.83$, p 0.01 vs HR $0.65,95 \% \mathrm{Cl} 0.47-$ $0.91, \mathrm{p} 0.01$.

Conclusion: Despite lower attainment of LLDAS in patients with higher disease activity at baseline, the magnitude of association of LLDAS attainment with lower damage accrual was greater in this subgroup of patients compared to those less active baseline disease. This supports the validity of LLDAS as an outcome measure, in a population similar to that typically selected into clinical trials, and further highlights the potential impact of achieving a target outcome in SLE patients with active disease.

Disclosure of Interests: Vera Golder: None declared, Eric F. Morand Grant/ research support from: AstraZeneca, Bristol Myers Squibb, Janssen, Merck Serono, and UCB, Consultant for: AstraZeneca, Eli Lilly, Janssen, and Merck Serono, Speakers bureau: AstraZeneca, Rangi Kandane-Rathnayake: None declared, Molla Huq: None declared, Hieu Nim: None declared, Worawit Louthrenoo: None declared, Shue Fen Luo: None declared, Yeong-Jian Wu: None declared, Aisha Lateef : None declared, Sargunan Sockalingam: None declared, Sandra Navarra: None declared, Leonid Zamora: None declared, Laniyati Hamijoyo: None declared, Yasuhiro Katsumata: None declared, masayoshi harigai Grant/research support from: Tokyo Women's Medical University (TWMU) has received unrestricted research grants for Division of Epidemiology and Pharmacoepidemiology of Rheumatic Diseases from Ayumi Pharmaceutical Co. Ltd. Bristol Meyers Squib, Chugai Pharmaceutical Co. Ltd., Nippon Kayaku Co. Ltd., Taisho Toyama Pharmaceutical Co. Ltd., Mitsubishi Tanabe Pharma Corp., and with which TWMU paid the salary of $\mathrm{MH}$. MH has also received research grants from AbbVie Japan GK, Eisai Co. Ltd., Takeda Pharmaceutical Co., Ltd., and Teijin Pharma Ltd., Madelynn Chan: None declared, Sean O'Neill: None declared,
Fiona Goldblatt: None declared, Chak Sing Lau: None declared, Zhanguo Li: None declared, Alberta Hoi Grant/research support from: GSK, AstraZeneca, UCB and Merck Serono, Consultant for: Janssen Steering Committee, Speakers bureau: Novartis, Mandana Nikpour: None declared DOI: 10.1136/annrheumdis-2019-eular.4457

\section{OP0247 EFFECT OF IMMUNOSUPPRESSIVE DRUG WITHDRAWAL ON DAMAGE PROGRESSION AND FLARE OCCURRENCE IN SLE PATIENTS IN REMISSION}

Margherita Zen, Francesca Saccon, Mariele Gatto, Maddalena Larosa, Francesco Benvenuti, Luca laccarino, Andrea Doria. University of Padova, Rheumatology Unit - Department of Medicine (DIMED), PADOVA, Italy

Background: Patients with Systemic Lupus Erythematosus (SLE) are often treated with prolonged maintenance therapy with immunosuppressants (ISs) after remission achievement, with the aim of avoiding disease flares and subsequent organ damage. Data on the risk of flare after IS discontinuation and the effect of IS discontinuation on damage accrual are scanty.

Objectives: Our aims were to analyze damage progression in remitted SLE patients who did or did not discontinued ISs, to assess flare rate after IS withdrawal and to compare damage accrual in patients who did or did not flare after IS discontinuation

Methods: We considered all SLE patients included in our lupus database, diagnosed between 1990 and 2018 (ACR criteria), treated with immunosuppressants over their disease course, who discontinued IS due to remission. IS discontinuation was defined as complete withdrawal of any immunosuppressive drug, and remission as clinical SLE Disease Activity Index (SLEDAI)-2K=0. Flares were defined according to SLEDAI Flare Index, and damage according to SLICC damage Index (SDI).

Results: Eligible patients ever treated with ISs were 319 out of 456 (69.9\%) currently in follow-up. Remission lasting at least 6 months was achieved by 206 patients treated with IS (64.6\%) (Table 1); among them $105(51 \%)$ discontinued ISs during the follow-up. Mean \pm SD follow-up after IS withdrawal was $91 \pm 71$ months (range 6-372). No difference in damage accrual between remitted patients who discontinued or did not discontinue ISs was observed at the end of follow-up, after adjusting for disease duration: median (range) SDI 1 (0-6) and 0 (0-4), respectively. Accordingly, the proportion of remitted patients who accrued damage during the follow-up was similar between those who did or did not discontinue ISs (55\% vs. 48\%). Among patients who discontinued ISs, 26 (24.7\%) experienced a flare after a median (range) of 57 (6-264) months from IS discontinuation. Flares were severe in $50 \%$ of cases (Table 2). No difference in damage progression between patients who flared and did not flare after IS withdrawal was found at the end of follow-up: median (range) SDI $1(0-5)$ and $1(0-6)$, respectively. Moreover, the proportion of patients with damage accrual was similar among patients with and without flare after IS discontinuation ( $56 \%$ vs. $54 \%$ ).

Table 1. Characteristics of remitted patients according to the discontinuation of ISs. Data are expressed as mean \pm SD or number (\%).

\begin{tabular}{|c|c|c|c|}
\hline & \multicolumn{2}{|c|}{ Remitted patients } & \multirow{2}{*}{$\begin{array}{c}P \\
\text { value }\end{array}$} \\
\hline & $\begin{array}{c}\text { IS } \\
\text { discontinued } \\
(105)\end{array}$ & $\begin{array}{c}\text { IS not } \\
\text { discontinued } \\
(101)\end{array}$ & \\
\hline Female, N (\%) & $93(88.6)$ & $85(84.1)$ & n.s. \\
\hline Age at 2018 , years & $44 \pm 11$ & $40 \pm 12$ & 0.035 \\
\hline SLE duration at 2018 , years & $19.5 \pm 9.2$ & $12.3 \pm 8.7$ & 0.027 \\
\hline SLE duration at remission, years & $5.2 \pm 6.1$ & $6.3 \pm 4.2$ & n.s. \\
\hline $\begin{array}{l}\text { Remission lasting at IS discontinuation }>2 \\
\text { consecutive years, } N(\%)\end{array}$ & $66(63)$ & $36(35.6)$ & 0.001 \\
\hline \multicolumn{4}{|l|}{ Reason for IS therapy, N (\%) } \\
\hline Lupus Nephritis & $68(64.8)$ & $57(56.4)$ & n.s. \\
\hline Skin involvement & $6(5.7)$ & $7(6.9)$ & \\
\hline Arthritis & $12(11.4)$ & $15(14.4)$ & \\
\hline Haematological involvement & $5(4.7)$ & $8(7.9)$ & \\
\hline Neuropsychiatric involvement & $3(2.9)$ & $2(1.9)$ & \\
\hline Vasculitis & $3(2.9)$ & $1(0.9)$ & \\
\hline Multisystemic involvement & $8(7.6)$ & $11(11)$ & \\
\hline \multicolumn{4}{|l|}{ Type of last IS*, N (\%) } \\
\hline Mycophenolate & $48(45.7)$ & $73(72.2)$ & 0.001 \\
\hline Azathioprine & $30(28.6)$ & $18(17.8)$ & 0.04 \\
\hline Methotrexate & $14(13.3)$ & $5(4.9)$ & 0.008 \\
\hline Cyclosporine & $7(6.7)$ & $4(3.9)$ & n.s. \\
\hline Cyclophosphamide & $6(5.7)$ & $1(0.9)$ & 0.001 \\
\hline
\end{tabular}

* last IS used before withdrawal or at last visit. Multisystemic: involvement of more than 2 organs requiring IS therapy. 